\title{
Central Nervous System Lymphoma
}

National Cancer Institute

\section{Source}

National Cancer Institute. Central Nervous System Lymphoma. NCI Thesaurus. Code C9301.

A non-Hodgkin or Hodgkin lymphoma that arises in the brain or spinal cord as a primary lesion. There is no evidence of lymphoma outside the central nervous system at the time of diagnosis. 